\title{
Haemodynamic effects of glyceryl trinitrate during continuous 24 hour infusion in patients with heart failure
}

Stefano Ghio, Arnaldo Poli, Maurizio Ferrario, Carlo Campana, Paolo Diotallevi, Ermanno Eleuteri, Antonio Mussini, Giuseppe Specchia, Carlo Montemartini

\begin{abstract}
Objective-To investigate whether the susceptibility to tolerance to glyceryl trinitrate is similar in different vascular beds in patients with chronic heart failure.

Patients-Twenty patients with heart failure underwent a continuous infusion of glyceryl trinitrate over 24 hours followed by administration of $\mathbf{N}$-acetylcysteine ( $5 \mathrm{~g}$ intravenously) in a bolus.

Main outcome measures-Haemodynamic measurements under control conditions, at peak titration of glyceryl trinitrate at 24 hours, and after $\mathbf{N}$-acetylcysteine; plasma renin activity and packed cell volume.

Results-After 24 hours of infusion the acute reduction in right atrial pressure had largely waned, while pulmonary vascular resistance remained improved and systemic resistance, which was not reduced at peak titration, significantly decreased with respect to control conditions. The effects of $\mathrm{N}$-acetylcysteine and hormonal responses were different in patients who did and did not develop tolerance to glyceryl trinitrate.

Conclusions-The haemodynamic profile of glyceryl trinitrate changed substantially during the study from a predominantly venodilator action at peak titration to a predominantly arteriolar dilatation after $\mathbf{2 4}$ hours of infusion. The different effects of $\mathbf{N}$-acetylcysteine and the different hormonal responses confirm the multifactorial pathogenesis of tolerance to glyceryl trinitrate.
\end{abstract}

(Br Heart f 1994;72:145-149)

Although the development of tolerance to the haemodynamic effects of glyceryl trinitrate in patients with chronic heart failure has been extensively described, ${ }^{1-3}$ the extent to which the effects attenuate in different parts of the circulation in humans is still controversial. Leier et al reported preferential tolerance in systemic than in pulmonary arterial circulation during long term treatment with isosorbide dinitrate in patients with congestive heart failure. ${ }^{4}$ Makhoul et al observed a greater degree of tolerance during infusion of glyceryl trinitrate for 24 hours in right heart pressures than for left heart haemodynamics in nine patients with heart failure. ${ }^{5}$ The common view, however, is that tolerance develops concomitantly in the venous and arterial circulation. ${ }^{6}$

Accordingly, we evaluated the haemodynamic response to a continuous infusion of glyceryl trinitrate over 24 hours in patients with chronic heart failure to determine whether the susceptibility to the development of tolerance is different in the venous bed and in the pulmonary and systemic arteriolar circulation. At the end of the infusion $\mathrm{N}$-acetylcysteine was administered and blood samples were drawn for measurement of plasma renin activity and the packed cell volume to evaluate the possible underlying mechanisms.

\section{Patients and methods}

PATIENTS

We studied 20 patients $(12$ men and 8 women, age range 39-62 years) with moderate to severe heart failure undergoing diagnostic right heart catheterisation. The aetiology of the disease was primary dilated cardiomiopathy in 15 patients and advanced coronary artery disease with severe reduction in left ventricular function in five. Ejection fraction at left ventriculography was $21 \%$ (SE $2 \%$ ). Thirteen patients were receiving oral digoxin and all were receiving oral furosemide at a daily maintenance dose of $40-250 \mathrm{mg}$. The patients continued to take digoxin and frusemide during the study, but treatment with angiotensin converting enzyme inhibitors was discontinued at least four days before the study and all other vasodilators, including nitrates, were discontinued at least 48 hours before the study. Patients gave informed consent before the study.

\section{METHODS}

Diagnostic right heart catheterisation was performed in all patients during the morning. Patients were then moved to the coronary care unit, where a Swan Ganz catheter was positioned in the pulmonary artery for measurements of right heart pressures and cardiac output by thermodilution. The study began in the afternoon, after the patients had rested in bed for 5-6 hours. The following haemodynamic variables were evaluated: right atrial (RAP), pulmonary artery (PAP), and pulmonary capillary wedge (PCWP) pressures; systemic blood pressure (by cuff); heart rate, cardiac output ( $\mathrm{CO}$, average of three consecutive measurements); cardiac index $(\mathrm{CI}=\mathrm{CO} /$ body surface area $)$, systemic vascular resistance $(S V R, 80 \times($ mean arterial pressure - RAP)/CO); and pulmonary 
Table 1 Mean (SE) changes in haemodynamic variables during study

\begin{tabular}{|c|c|c|c|c|c|c|c|c|}
\hline & $\begin{array}{l}\text { Heart rate } \\
\text { (beats/min) }\end{array}$ & $\begin{array}{l}\text { Blood pressure } \\
(\mathrm{mm} \mathrm{Hg})\end{array}$ & $\begin{array}{l}\text { Right atrial } \\
\text { pressure } \\
(\mathrm{mm} \mathrm{Hg})\end{array}$ & $\begin{array}{l}\text { Pulmonary artery } \\
\text { pressure } \\
(\mathrm{mm} \mathrm{Hg})\end{array}$ & $\begin{array}{l}\text { Pulmonary vascular } \\
\text { resistance } \\
\left(\text { dymes } / \mathrm{s} / \mathrm{cm}^{5}\right)\end{array}$ & $\begin{array}{l}\text { Systemic vascular } \\
\text { resistance } \\
\left(\text { dynes } / \mathrm{s} / \mathrm{cm}^{5}\right)\end{array}$ & $\begin{array}{l}\text { Pulmonary capillary } \\
\text { wedge pressure } \\
(\mathrm{mm} \mathrm{Hg})\end{array}$ & $\begin{array}{l}\text { Cardiac index } \\
\left(\mathrm{l} / \mathrm{min} / \mathrm{m}^{2}\right)\end{array}$ \\
\hline $\begin{array}{l}\text { Control } \\
\text { Titration } \\
24 \text { hours } \\
\text { N-acetylcysteine } \\
\text { F test }\end{array}$ & $\begin{array}{c}83.2(3.5) \\
82.6(3.0) \\
87 \cdot 3(3.4) \\
87.5(3.3) \\
4.4\end{array}$ & $\begin{array}{c}117 \cdot 8(3.2) \\
106.3(3.7) \\
112.8(2.3) \\
112.5(3.4) \\
8.0\end{array}$ & $\begin{array}{c}6.2(1.0) \\
2.4(0.5) \\
5.0(0.9) \\
4.9(0.8) \\
11.0\end{array}$ & $\begin{array}{c}49 \cdot 8(4 \cdot 9) \\
33 \cdot 6(3 \cdot 6) \\
38 \cdot 1(4 \cdot 0) \\
42 \cdot 4(4 \cdot 0) \\
33\end{array}$ & $\begin{array}{c}224(31) \\
155(22) \\
152(23) \\
140(20) \\
11\end{array}$ & $\begin{array}{c}1520(61) \\
1426(64) \\
1280(83) \\
1236(79) \\
8 \cdot 8\end{array}$ & $\begin{array}{c}20 \cdot 3(2 \cdot 1) \\
12 \cdot 4(1 \cdot 6) \\
16 \cdot 2(1 \cdot 9) \\
19 \cdot 3(2 \cdot 2) \\
22\end{array}$ & $\begin{array}{c}3 \cdot 2(0 \cdot 5) \\
2 \cdot 6(0 \cdot 1) \\
3 \cdot 0(0 \cdot 2) \\
3 \cdot 2(0 \cdot 2) \\
0.9\end{array}$ \\
\hline
\end{tabular}

vascular resistance (PVR, $80 \times($ mean PAPPCWP)/CO). Haemodynamic measurements were obtained at baseline; at peak glyceryl trinitrate titration, after 24 hours and $10 \mathrm{~min}$ utes after $\mathrm{N}$-acetylcysteine administration. Glyceryl trinitrate was infused intravenously by means of a calibrated pump at a rate of 10 $\mu \mathrm{g} / \mathrm{min}$, the dosage increasing progressively by $20-40 \mu \mathrm{g} / \mathrm{min}$ every $5-10$ minutes; the end point of glyceryl trinitrate titration was a $30 \%$ reduction in PAP or a $20 \%$ reduction in PCWP without having reduced systolic pressure to less than $90 \mathrm{~mm} \mathrm{Hg}$. Glyceryl trinitrate infusion continued at the same dosage

Figure 1 Mean (SE) changes in right atrial pressure (RAP), systemic vascular resistance $(S V R)$, and pulmonary vascular resistance (PVR) during infusion. $C$, control conditions; $T$, peak nitroglycerin titration; NAC, $N$ acetylcysteine. ${ }^{\star} P<0.05$ v previous value.
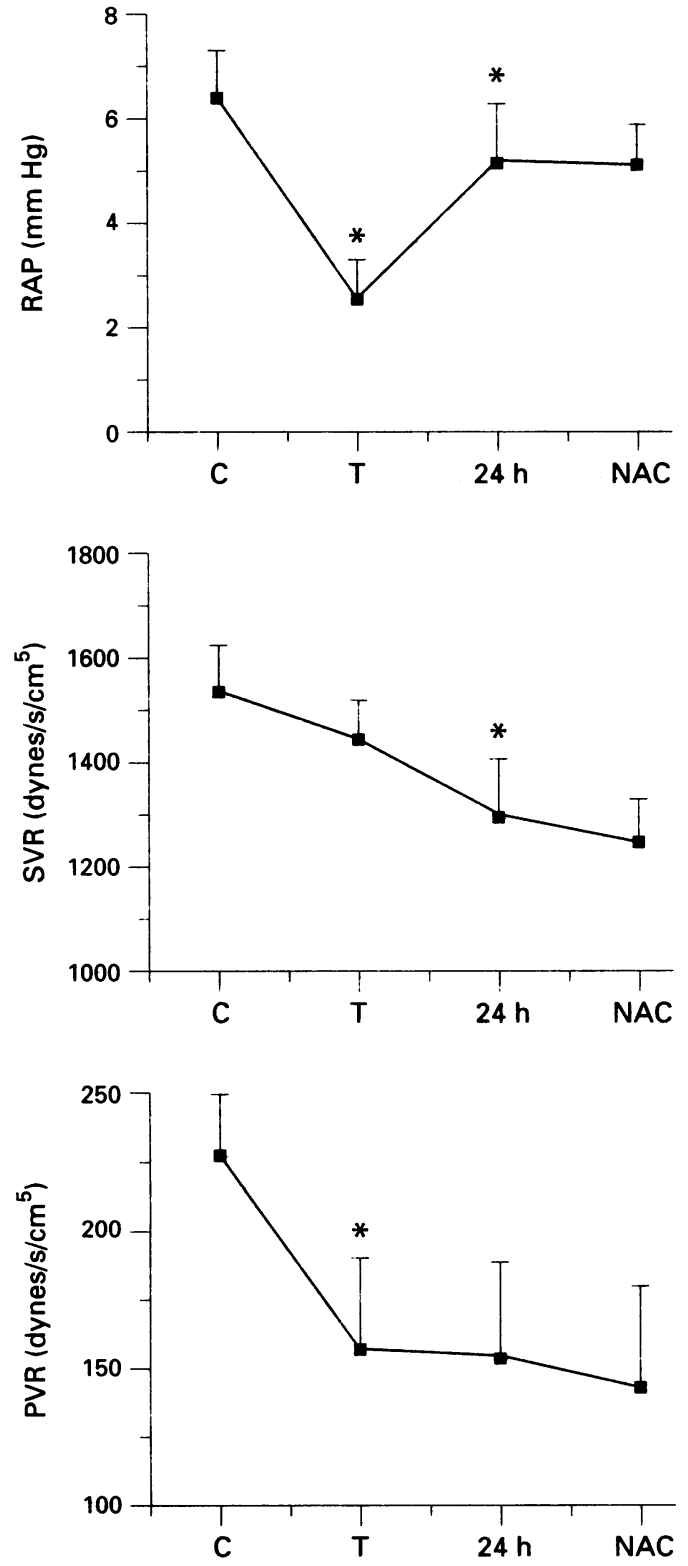

for 24 hours. After the 24 hours haemodynamic measurements, $\mathrm{N}$-acetylcysteine was administered intravenously ( $5 \mathrm{~g}$ in $100 \mathrm{ml} \mathrm{5 \%}$ dextrose in water, given over 20 minutes), while continuing to infuse glyceryl trinitrate. $\mathrm{N}$-acetylcysteine preparations were supplied by Zambon Group SpA, Milan. Blood samples were drawn under control conditions, at the end of glyceryl trinitrate titration, and after 24 hours of infusion for determination of plasma renin activity (radioimmunoassay) and the packed cell volume.

\section{TOLERANCE}

The effects of $\mathrm{N}$-acetylcysteine, as well as the changes in packed cell volume and plasma renin activity, were evaluated in patients with and without tolerance to glyceryl trinitrate in the venous bed or in the systemic and pulmonary arterial bed (using RAP as indicator of the venous effects of glyceryl trinitrate and SVR and PVR as indicators of glyceryl trinitrate action on systemic and pulmonary arterioles). We therefore defined tolerance in each patient and for each haemodynamic variable as a $>20 \%$ loss of the acute effects of triglyceryl nitrate provided that the drug modified the given variable at peak titration by at least $20 \%$.

\section{STATISTICAL ANALYSIS}

Data are expressed as means (SE). Sequential data obtained in the different phases of the protocol were analysed by a repeated measures analysis of variance followed, when a significant change was found, by Scheffé's multiple comparison test. Changes in plasma renin activity and packed cell volume at 24 hours with respect to control conditions were evaluated by a paired $t$ test. The effects of $\mathrm{N}$-acetylcysteine in different subgroups of patients with or without tolerance to glyceryl trinitrate were also evaluated by a paired $t$ test.

\section{Results}

HAEMODYNAMIC MEASUREMENTS (TABLE 1, FIGURE 1)

Glyceryl trinitrate was infused at a mean dosage of $85(13) \mu \mathrm{g} / \mathrm{min}$. Heart rate did not change significantly during the study period. Systolic blood pressure decreased by an average of $10 \%$ at peak titration and was slightly increased after 24 hours but not modified by $\mathrm{N}$-acetylcysteine (these changes did not reach significance). Right atrial pressure decreased by an average $61 \%$ at peak titration $(P<$ $0.05)$; after 24 hours most of this effect was 

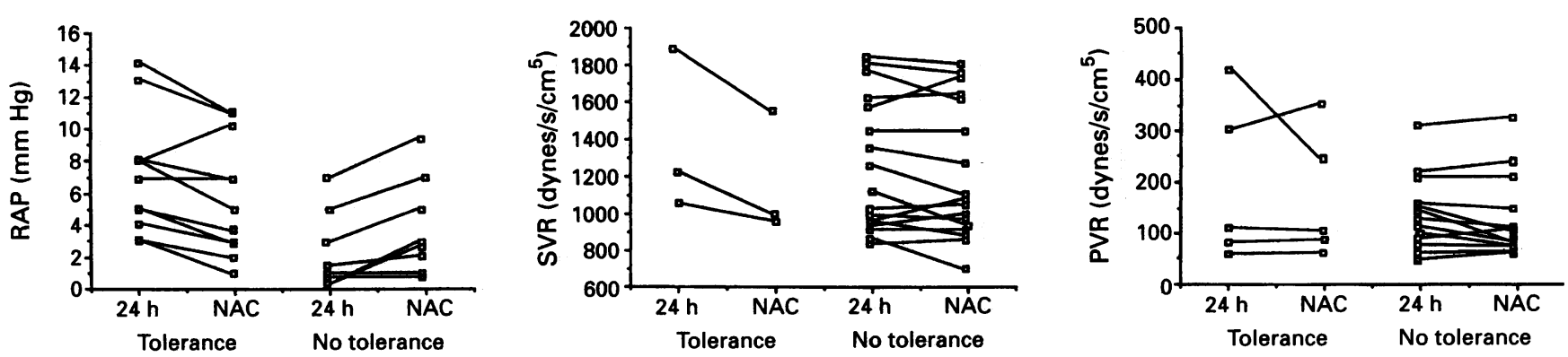

Figure 2 Individual changes in right atrial pressure (RAP), systemic vascular resistance (SVR), and pulmonary vascular resistance (PVR) after $N$ acetylcysteine (NAC) administration in patients who developed and did not develop tolerance to glyceryl trinitrate during infusion.

lost $(-19 \% v$ control, $\mathrm{P}<0.05 v$ peak titration); no change occurred after $\mathrm{N}$-acetylcysteine. Pulmonary artery pressure showed a $33 \%$ decrease at peak titration $(P<0.05)$; after 24 hours it increased slightly $(9 \%, \mathrm{P}<$ $0.05 v$ peak titration), increasing further after $\mathrm{N}$-acetylcysteine (9\%, $\mathrm{P}<0.05 v 24$ hours). Pulmonary capillary wedge pressure decreased by an average $39 \%$ at peak titration $(P<0.05)$; at 24 hours it was significantly increased with respect to peak titration $(\mathbf{P}<$ 0.05 ) and further increased after $\mathrm{N}$-acetylcysteine ( $\mathrm{P}<0.05 v 24$ hours). Pulmonary vascular resistance significantly decreased at peak titration $(-31 \%, P<0.05)$; no further change occurred after 24 hours and after $\mathrm{N}$-acetylcysteine. Cardiac index showed no significant change during glyceryl trinitrate infusion. Systemic vascular resistance showed a slight decrease at peak titration $(-6 \%, \mathrm{NS})$; after 24 hours, however, this resistance was significantly lower than under control conditions $(-16 \%, P<0.05)$; no change occurred after $\mathrm{N}$-acetylcysteine.

EFFECTS OF N-ACETYLCYSTEINE

Figure 2 shows individual changes after Nacetylcysteine administration in patients with or without glyceryl trinitrate tolerance in the venous bed or in the systemic or pulmonary arteriolar circulation. Venous tolerance was found in 12 patients. $\mathrm{N}$-acetylcysteine significantly decreased right atrial pressure in patients with venous tolerance (from 6.9 $(1.0)$ to $5.7(1.0) \mathrm{mm} \mathrm{Hg}, \mathrm{P}<0.05)$, but it increased right atrial pressure in patients without venous tolerance (from $1.9(1.0)$ to 3.7 $(1.1) \mathrm{mm} \mathrm{Hg}, \mathrm{P}<0.05)$. Systemic arteriolar tolerance was found in 3 patients and pulmonary arteriolar tolerance in 5; because the patients with systemic or pulmonary arteriolar tolerance were few the statistical evaluation of $\mathrm{N}$-acetylcysteine effects was performed on

Table 2 Changes in packed cell volume and plasma renin activity in whole population and patients according to presence of venous or arteriolar tolerance

\begin{tabular}{|c|c|c|c|c|c|}
\hline & \multirow[b]{2}{*}{ All patients } & \multicolumn{2}{|c|}{ Venous tolerance } & \multicolumn{2}{|c|}{ Arteriolar tolerance. } \\
\hline & & Yes & No & Yes & No \\
\hline \multicolumn{6}{|c|}{ Packed cell volume } \\
\hline $\begin{array}{l}\text { Control } \\
24 \text { hours } \\
\mathrm{P} \text { value }\end{array}$ & $\begin{array}{l}39.4(0.9) \\
35.5(1.1) \\
<0.01\end{array}$ & $\begin{array}{l}39.8(1.4) \\
35.7(1.6) \\
<0.01\end{array}$ & $\begin{array}{l}39.0(1.3) \\
35.1(1.4) \\
<0.01\end{array}$ & $\begin{array}{l}39.9(2.4) \\
36.4(2.9) \\
<0.01\end{array}$ & $\begin{array}{l}39.2(1.0) \\
35.1(1.0) \\
<0.01\end{array}$ \\
\hline \multicolumn{6}{|c|}{ Plasma renin activity } \\
\hline $\begin{array}{l}\text { Control } \\
24 \text { hours } \\
\text { P value }\end{array}$ & $\begin{array}{l}5.9(1.4) \\
7.5(1.8) \\
0.08\end{array}$ & $\begin{array}{l}5 \cdot 5(1 \cdot 8) \\
8 \cdot 0(2 \cdot 3) \\
<0.02\end{array}$ & $\begin{array}{l}6 \cdot 7(2 \cdot 3) \\
6 \cdot 8(2.9) \\
\text { NS }\end{array}$ & $\begin{array}{l}4.5(2 \cdot 7) \\
8 \cdot 0(3 \cdot 8) \\
0.08\end{array}$ & $\begin{array}{l}6 \cdot 7(1 \cdot 7) \\
7 \cdot 2(2 \cdot 1) \\
\text { NS }\end{array}$ \\
\hline
\end{tabular}

pooled data for systemic and pulmonary resistance. $\mathrm{N}$-acetylcysteine significantly decreased systemic and pulmonary vascular resistance $(P<0.05)$ when the effects of glyceryl trinitrate on either or both became attenuated but it did not change these resistances otherwise.

PLASMA RENIN ACTIVITY AND PACKED CELL VOLUME (TABLE 2)

In the whole population plasma renin activity showed a non-significant increase $(26 \%, P=$ 0.08 ) at the end of the infusion period. Plasma renin activity significantly increased, however, in patients with venous tolerance $(47 \%, P<0.02)$ but not in those without such tolerance. Plasma renin activity also tended to increase in patients who developed systemic or pulmonary arteriolar tolerance, or both $38 \%, P=0.08 v$ control) but not in the other patients. Packed cell volume significantly decreased in the whole population $(-10 \%, P<0.01)$ and in all subgroups of patients irrespective of the presence of tolerance to glyceryl trinitrate. Body weight showed a non-significant increase, from 65.9 $(1 \cdot 8)$ to $66 \cdot 2(1 \cdot 8) \mathrm{kg}$.

\section{Discussion}

\section{DIFFERENTIAL TOLERANCE}

Although continuous treatment with organic nitrates can rapidly lead to the development of tolerance in patients with heart failure, it is still controversial whether tolerance to glyceryl trinitrate develops concomitantly in all parts of the circulation. Olivari et al measured sequential haemodynamic variables in nine patients with congestive heart failure who received a $30-40 \mathrm{~cm}^{2}$ transdermal preparation of glyceryl trinitrate; after 24 hours, the initial large decrease in right atrial pressure had completely waned but mean pulmonary pressure remained lower than under control conditions; systemic vascular resistance tended to decrease progressively during the 24 hours of the study without reaching significance. ${ }^{7}$ Leier et al, however, noticed a preferential tolerance in the systemic arterial circulation in 13 patients with congestive heart failure. ${ }^{4}$ After 12 weeks of treatment with isosorbide dinitrate $40 \mathrm{mg}$ four times a day resting and exercise systemic vascular resistance at rest and on exercise returned to control values while pulmonary artery pressure and pulmonary vascular resistance remained improved; they did not, however, report the effects of nitrates on 
right atrial pressure. Makhoul et al noticed a higher degree of tolerance in the venous and pulmonary circulation than in the systemic arterial bed in nine patients with congestive heart failure who underwent a continuous infusion of glyceryl trinitrate over 24 hours. $^{5}$ In our patients the important reduction of right atrial pressure observed at peak glyceryl trinitrate titration had largely waned by 24 hours; on the contrary, pulmonary vascular resistance remained improved and at the same time systemic vascular resistance, which was not significantly reduced at peak titration, was significantly lower than under control conditions. Therefore, the haemodynamic profile of the drug substantially changed during the time course of the study, shifting from a predominantly venodilator action at peak titration to a predominantly pulmonary and systemic arteriolar vasodilator action after 24 hours of infusion. These observations are in accordance with previous data obtained in animals, ${ }^{8}$ healthy humans, ${ }^{9}$ and patients with ischaemic heart disease, ${ }^{10}$ indicating preferential venous tolerance during continuous nitrate treatment.

Our results also show that the vasodepressor effects of glyceryl trinitrate attenuate more rapidly in the venous bed than in the pulmonary circulation. Veins therefore seem to be both the primary site of action of nitrates $^{11-12}$ and the first organ to become unresponsive to nitrates during continuous exposure. An important limitation is that the haemodynamic we measured do not permit a precise evaluation of glyceryl trinitrate's action on large conductance arteries; this would have correctly required the calculation of arterial compliance. Dilatation of conductance arteries is another pharmacological effect of glyceryl trinitrate ${ }^{13}$ with an important role in hypertensive patients and in patients with ischaemic heart disease ${ }^{14-16}$; its relevance in patients with heart failure is still unknown.

\section{EFFECTS OF N-ACETYLCYSTEINE}

The administration of $\mathrm{N}$-acetylcysteine in a bolus significantly decreased right atrial pressure in the patients in whom the acute effects of glyceryl trinitrate on right atrial pressure were attenuated at the end of the infusion period (partially reversing tolerance). Nacetylcysteine, however, significantly increased right atrial pressure in all other patients; this paradoxical effect may be due to the haemodynamic load imposed by the bolus intravenous infusion of a bolus of $\mathrm{N}$-acetylcysteine $(100-150 \mathrm{ml})$ in patients with compromised ventricular function. Such an effect was probably overwhelmed by the beneficial action of the sulphydryl donor in patients with tolerance. $\mathrm{N}$-acetylcysteine also decreased systemic and pulmonary vascular resistance whenever the effects on arteriolar resistances were attenuated but not otherwise. These results confirm that the depletion of intracellular sulphydryl groups is one of the pathogenetic factors responsible for the development of nitrate tolerance in patients with heart failure. ${ }^{1} \mathrm{~A}$ limitation of our study is that we cannot say whether depletion of sulphydryl groups plays a greater part in arterial or venous tolerance in these patients.

\section{ROLE OF RENIN-ANGIOTENSIN SYSTEM AND}

\section{PLASMA EXPANSION}

The activation of reflex vasoconstrictive forces (including the sympathetic system and the renin-angiotensin system) that offset the initial vasodilatation induced by nitrates has been suggested as a primary mechanism for the development of tolerance to these drugs, both in experimental animals ${ }^{817}$ and in patients with heart failure. ${ }^{13}$ In other clinical studies, however, circulating catecholamine concentrations and plasma renin activity did not increase during nitrate treatment. ${ }^{218}$ In our population plasma renin activity did not show a significant increase after 24 hours of glyceryl trinitrate infusion; the role of the renin-angiotensin system is shown, however, by the fact that plasma renin activity significantly increased in patients with venous tolerance and also tended to increase in those with arteriolar tolerance without changing in patients who did not develop tolerance. Thus, the activation of the renin-angiotensin system added to the depletion of intracellular sulphydryl groups to determine the development of glyceryl trinitrate tolerance, at least in the venous bed. Interestingly, treatment with angiotensin converting enzyme inhibitors drugs completely prevented tolerance glyceryl trinitrate tolerance in the forearm venous circulation of healthy volunteers. ${ }^{19}$ The point, however, is still controversial as the concomitant administration of captopril and high dose intravenous nitroglycerin failed to alter the extent of nitrate tolerance in nine patients with heart failure, although captopril effectively prevented the increase of plasma renin activity in these patients. ${ }^{20}$

The packed cell volume decreased in all subgroups of patients, irrespective of the presence of tolerance. As body weight tended to increase in our patients at the end of the 24 hour infusion period, the decrease in packed cell volume was probably due also to the intravenous fluid administration itself. The data suggest that the increase in intravascular volume cannot be considered in itself a sufficient factor for the development of tolerance to glyceryl trinitrate though it may be a necessary cofactor.

In conclusion, in patients with chronic heart failure a higher susceptibility to the development of glyceryl trinitrate tolerance was observed in the venous bed than in the pulmonary or systemic arteriolar circulation. The haemodynamic profile of the drug therefore shifted from a predominant venodilator action at peak titration to a predominant arteriolar dilatation after 24 hours of continuous infusion. The fact that tolerance is not an all or none phenomenon but may affect different vascular beds to a different extent in individual patients is a possibility that must be taken into consideration to interpret the effects of long term nitrate treatment in patients with chronic heart failure. 
1 Packer M, Wai Hung L, Kessler PD, Gottlieb SS, Medina N, Yushak M. Prevention and reversal of nitrate tolerance in patients with congestive heart failure. $N$ Engl $\mathcal{F}$ Med 1987;317:799-804.

2 Elkayam U, Kulick D, McIntosh N, Roth A, Hsueh W, Rahimtoola SH. Incidence of early tolerance to hemodynamic effects of continuous infusion of nitroglycerin in patients with coronary artery disease and heart failure. Circulation 1987;76:577-84.

3 Dupuis J, Lalonde G, Lemieux R, Rouleau JL. Tolerance to intravenous nitroglycerin in patients with congestive heart failure: role of increased intravascular volume, neurohumoral activation and lack of prevention with $\mathrm{N}-$ acetylcysteine 7 Am Coll Cardiol 1990;16:923-31.

4 Leier CV, Huss P, Magorien RD, Unverferth DV. Improved exercise capacity and differing arterial and Improved exercise capacity and differing arterial and therapy for congestive heart failure. Circulation 1983; therapy for

5 Makhoul N, Dakak N, Flugelman MY, Merdler A, Shefer A, Schneeweiss A, et al. Nitrate tolerance in heart failA, Schneeweiss A, et al. Nitrate tolerance in heart failure: differential venous, pulmonary and

6 Elkayam U. Tolerance to organic nitrates: evidence, mechanisms, clinical relevance and strategies for prevention. anisms, clinical relevance and strate

7 Olivari MT, Carlyle PF, Levine B, Cohn JN. Hemodynamic and hormonal response to transdermal nitroglycerin in normal subjects and in patients with congestive heart failure. $\mathcal{F} \mathrm{Am}$ Coll Cardiol 1983;2:872-8.

8 Stewart DJ, Elsner D, Sommer O, Holtz J, Bassenge E. Altered spectrum of nitroglycerin action in long term treatment: nitroglycerin-specific venous tolerance with maintenance of arterial vasodepressor potency.
Circulation 1986;74:573-82.

9 Zelis R, Mason DT. Isosorbide dinitrate. Effect on the vasodilator response to nitroglycerin. $\mathcal{F} A M A 1975 ; 234$ : 166-70.

10 Ghio S, De Servi S, Perotti R, Eleuteri E, Montemartini C, Specchia G. Different susceptibility to the develop- ment of nitroglycerin tolerance in the arterial and venous circulation in humans. Effects of $\mathrm{N}$-acetylcysteine administration. Circulation 1992;86:798-802.

11 Imhof PR, Ott B, Frankhauser P, Chu L-C, Hodler J. Difference in nitroglycerin dose response in the venous and arterial beds. Eur $f$ Clin Pharmacol 1980;18 $455-60$.

12 Abrams J. Hemodynamic effects of nitroglycerin and long acting nitrates. Am Heart 7 1985;110:216-24

13 Feldman RL, Pepine CJ, Conti CR. Magnitude of dilatation of large and small arteries by nitroglycerin. tion of large and small

14 Simon ACh, Levenson JA, Levy BY, Bouthier JE, Peronneau PP, Safar ME. Effect of nitroglycerin on peripheral large arteries in hypertension. $\mathrm{Br} \mathcal{F} \mathrm{Clin}$ Pharmacol 1982;14:241-6.

15 Brown BG, Lee AB, Bolson EL, Dodge HT. Reflex constriction of significant coronary stenoses as a mechanism contributing to ischemic left ventricular dysfunction during isometric exercise. Circulation 1984;70:18-24.

16 Smulyan $H$, Mookherjee S, Warner R. The effect of nitroglycerin on forearm distensibility. Circulation 1986; glycerin on

17 Rush ML, Lang WJ, Rand MJ. Studies on compensatory reflexes and tolerance to glyceril trinitrate (GTN). Eur $\mathcal{F}$ Pharmacol 1971;16:148-55.

18 Elkayam U, Roth A, Mehra A, Ostrzega E, Shotan A, Kulick D, et al. Randomized study to evaluate the relation between oral isosorbide dinitrate dosing interval and the development of early tolerance to its effect on left ventricular filling pressure in patients with chronic heart failure. Circulation 1991;84:2040-8.

19 Katz RJ, Levy WS, Buff L, Wasserman AG. Prevention of nitrate tolerance with angiotensin converting enzyme inhibitors. Circulation 1991;83:1271-7.

20 Dakak N, Makhoul N, Flugeman MJ, Merdler A Shehadeh H, Schneeweiss A, et al. Failure of captopril to prevent nitrate tolerance in congestive heart failure secondary to coronary artery disease. Am F Cardiol 1990; 66:608-13. 